\title{
Implications of combined endocrinopathy of diabetes mellitus and hypothyroidism on pregnancy
}

\author{
Amudha P.*, Karthika Devi A., Manochithra B., Delphin Supriya J.
}

Department of Obstetrics and Gynecology, Thanjavur medical college, Thanjavur, Tamilnadu, India

Received: 16 November 2016

Accepted: 03 December 2016

\section{*Correspondence:}

Dr. Amudha P.,

E-mail: amudha70dr@gmail.com

Copyright: ( ) the author(s), publisher and licensee Medip Academy. This is an open-access article distributed under the terms of the Creative Commons Attribution Non-Commercial License, which permits unrestricted non-commercial use, distribution, and reproduction in any medium, provided the original work is properly cited.

\begin{abstract}
Background: Hypothyroidism and diabetes are the endocrine disorders commonly observed in pregnancy and each has been associated with adverse maternal and fetal outcomes. Our objective was to study the implications of combined endocrinopathy of hypothyroidism and DM on pregnancy and its outcome.

Methods: This prospective cohort study included 150 pregnant women with singleton gestation and who were screened for and diagnosed with DM and /or hypothyroidism. They were then divided into 3 groups: 1) Diabetes $(n=69)$ 2) Hypothyroidism $(n=53) 3)$ DM and hypothyroidism $(n=28)$. Perinatal and neonatal characteristics were compared among the 3 groups and statistically analysed.

Results: Women with both DM and hypothyroidism had higher rates of first trimester abortions, preeclampsia, polyhydramnios, placental abruption, preterm deliveries, caesarean sections, postpartum haemorrhage and intrauterine fetal deaths when compared to other groups. On the contrary, rates of labour induction, fetal macrosomia and LBW new-borns were not statistically significant among the groups.

Conclusions: Women with both DM and hypothyroidism are at high risk of developing perinatal complications and need intense surveillance for the same during their pregnancy for better outcome. Pregnant women diagnosed with one of these endocrinopathies should be screened for the other.
\end{abstract}

Keywords: Diabetes mellitus, Hypothyroidism, Pregnancy outcome

\section{INTRODUCTION}

Diabetes mellitus (DM) and hypothyroidism are the commonest endocrine disorders observed during pregnancy. Gestational diabetes (GDM) has been defined as any degree of carbohydrate intolerance that is first diagnosed during pregnancy. ${ }^{1}$ The prevalence of GDM ranges from $1 \%$ to $14 \%$ and it varies in direct proportion to the prevalence of Type $2 \mathrm{DM}$ and Impaired Glucose Tolerance in a population. ${ }^{1-3}$ GDM and pre GDM are associated with a host of adverse maternal outcomes like pre eclampsia, polyhydramnios, increased caesarean section rates, perinatal morbidity and mortality and increased neonatal morbidity which include shoulder dystocia, birth trauma, birth defects, metabolic complications, respiratory distress syndrome and prematurity. ${ }^{4-6}$
Hypothyroidism is the second most common endocrine disorder in pregnancy with an incidence of $2 \%-5 \%$. The common causes for hypothyroidism in pregnancy include autoimmune thyroiditis and therapeutic thyroid gland destruction for hyperthyroidism. ${ }^{7-9}$ Pregnant women with hypothyroidism have been reported to have a higher rate of abortions in first trimester, placental abruption, gestational hypertension and post-partum haemorrhage. ${ }^{10-}$ ${ }_{12}$ Though several authors have reported the association between various types of DM and hypothyroidism, the evidence regarding such an association is inconsistent. Moreover, data regarding the influence of the combination of these two endocrinopathies on pregnancy is also lacking. 
The aim of this study is to identify the implications of the dual endocrine disorders of DM and hypothyroidism on pregnancy and its outcome.

\section{METHODS}

This is a prospective study conducted in Government Raja Mirasudhar Hospital attached to Thanjavur Medical College, Thanjavur over a period of 1 year between August 2014 and July 2015. A total of 150 pregnant women with singleton gestation and screened for diagnosed with GDM and/or hypothyroidism were included in the study. Women with multifetal gestation, medical complications other than DM and hypothyroidism, previous thyroid surgeries and structural fetal anomalies were excluded from the study. Informed consent was obtained from all subjects included in the study.

Women with either DM or hypothyroidism alone were screened for the other and were then divided into the following 3 groups.

\section{Group $A[n=69]$}

Women diagnosed with GDM or preGDM by 75 grams GCT (DIPSI) and with normal thyroid function tests.

\section{Group $B$ [n=53]}

Women diagnosed with overt or subclinical hypothyroidism and in whom GDM and pre GDM were ruled out by 75 grams GCT.

\section{Group $C[n=28]$}

Women diagnosed with both diabetes and hypothyroidism.

Detailed history was elicited and clinical examination was done. They were followed up until delivery and the pregnancy outcomes including maternal and neonatal morbidity and mortality were studied. Statistical analysis was done on software EPI 2010 developed by CDC.

The study was approved by the Institutional Ethical Committee of Thanjavur Medical College.

\section{RESULTS}

A total of 150 women were included in the study and were segregated into 3 groups. Group A included 69 women (46\%) diagnosed with diabetes alone. Group B included 53 women $(35.3 \%)$ with hypothyroidism alone and Group C included 28 women (18.7\%) with both diabetes and hypothyroidism.

The mean age of the study subjects was $28 \pm 5.2$ in Group A, 25 \pm 4.6 in Group B and $27 \pm 5.1$ in Group C. On observing the parity distribution $64 \%(n=96)$ of the study population were multigravidae and Group A had the highest rate $(46.4 \%)$ of higher order parity women.

We observed that women in Group C (DM+ hypothyroidism) had a higher rate of treatment for infertility $(21.4 \%)$, spontaneous first trimester abortions $(9.3 \%)$ and previous preterm deliveries (13.2\%) (Table $1)$.

Table 1: Maternal demographic and past obstetric variables.

\begin{tabular}{|c|c|c|c|c|}
\hline Characteristic & $\begin{array}{l}\text { Diabetes } \\
\text { Gr A } \\
(n=69)\end{array}$ & $\begin{array}{l}\text { Hypothyroidism } \\
\text { Gr B } \\
(\mathbf{n}=\mathbf{5 3})\end{array}$ & $\begin{array}{l}\text { DM + } \\
\text { Hypothyroidism Gr C } \\
(\mathbf{n}=\mathbf{2 8})\end{array}$ & $\begin{array}{l}\text { Statistical } \\
\text { inference }\end{array}$ \\
\hline $\begin{array}{l}\text { Maternal Age } \\
\text { Mean } \pm \text { SD }\end{array}$ & $28 \pm 5.2$ & $25 \pm 4.6$ & $27 \pm 5.1$ & $\begin{array}{l}\mathrm{f}=1.084 \\
0.241>0.05 \\
\text { Not significant }\end{array}$ \\
\hline $\begin{array}{l}\text { Gravidity: } \\
\text { Primi } \\
\text { G3+ }\end{array}$ & $\begin{array}{l}31.9 \% \\
46.4 \%\end{array}$ & $\begin{array}{l}45.3 \% \\
26.4 \%\end{array}$ & $\begin{array}{l}28.6 \% \\
30.3 \% \\
\end{array}$ & \multirow{4}{*}{$\begin{array}{l}X^{2}=39.604 \\
D f=11 \\
0.012<0.05 \\
\text { significant }\end{array}$} \\
\hline $\begin{array}{l}\text { Treatment for } \\
\text { infertility }\end{array}$ & $15.1 \%$ & $13 \%$ & $21.4 \%$ & \\
\hline $\begin{array}{l}\text { Spontaneous } 1^{\text {st }} \\
\text { trimester abortions in } \\
\text { the past }\end{array}$ & $6.6 \%$ & $6.2 \%$ & $9.3 \%$ & \\
\hline $\begin{array}{l}\text { Previous preterm } \\
\text { deliveries }\end{array}$ & $8.4 \%$ & $7.8 \%$ & $13.2 \%$ & \\
\hline
\end{tabular}

Table 2 shows the perinatal characteristics. In our study, higher rate of severe pre-eclampsia $(28.6 \%)$ was observed in women with both diabetes and hypothyroidism ( $\mathrm{p}$ $<0.05$ ) while it was $14.5 \%$ and $13.2 \%$ in Group A and 
Group B respectively. But the rate of gestational hypertension was similar in women with diabetes alone $(14.5 \%)$ and in those with dual endocrinopathy (14.3\%). Of the 150 study subjects, 24\% $(n=36)$ developed hydramnios and the highest rate $(35.7 \%)$ was noted in women with both diabetes and hypothyroidism $(\mathrm{p}<0.05)$. Similarly women with dual endocrinopathy (Group C) also had higher rates of placental abruption (21.4\%) $(\mathrm{p}<0.05)$.

In our study, $13.3 \%$ of the subjects had preterm deliveries and rate of preterm deliveries was significantly high in women with dual endocrinopathy $(\mathrm{p}<0.05)$.

Table 2: Perinatal characteristics.

\begin{tabular}{|llll|}
\hline Characteristics & $\begin{array}{l}\text { DM } \\
\mathrm{n}=69\end{array}$ & $\begin{array}{l}\text { Hypothyroidism } \\
\mathrm{n}=\mathbf{5 3}\end{array}$ & $\begin{array}{l}\text { DM + hypothyroidism } \\
\mathrm{n}=\mathbf{2 8}\end{array}$ \\
\hline Severe Preeclampsia & $14.5 \%$ & $13.2 \%$ & $28.6 \%$ \\
\hline GHT & $14.5 \%$ & $9.4 \%$ & $14.3 \%$ \\
\hline Hydramnios & $24.6 \%$ & $17 \%$ & $35.7 \%$ \\
\hline Placental Abruption & $10.1 \%$ & $13.2 \%$ & $21.4 \%$ \\
\hline Preterm deliveries & $10.7 \%$ & $7.5 \%$ & $18.8 \%$ \\
\hline Labour inductions & $38.7 \%$ & $28.8 \%$ & $36 \%$ \\
\hline Caesarean sections & $36.2 \%$ & $30.8 \%$ & $48 \%$ \\
\hline PPH & $24.6 \%$ & $15.1 \%$ & $32 \%$ \\
\hline Intrauterine fetal death & $0 \%$ & $0 \%$ & $7.1 \%$ \\
\hline Macrosomia & $21.4 \%$ & $6.6 \%$ & $17.5 \%$ \\
\hline LBW $<2.5 \mathrm{Kg}$ & $9.3 \%$ & $8.8 \%$ & $9.1 \%$ \\
\hline
\end{tabular}

There was no significant difference in the labour induction rates between the diabetes group (38.7\%) and dual endocrinopathy group (36\%). Women with dual endocrinopathy needed higher rates of caesarean sections (48\%) which included both emergency and elective sections $(\mathrm{p}<0.05)$. Postpartum haemorrhage and intrauterine deaths were significantly higher in women with dual endocrinopathy, $32.1 \%$ and $7.1 \%$ respectively $(\mathrm{p}<0.05)$.

Women with diabetes alone (Group A) had higher rate of macrosomia $(21.4 \%)$ than the other groups . There was no significant difference in the incidence of low birth weight new-borns and the need for NICU admissions among the 3 groups.

\section{DISCUSSION}

Hypothyroidism and diabetes are the commonest endocrine disorders diagnosed during pregnancy. Both endocrinopathies have been found to be associated with adverse fetomaternal outcomes. The association between DM and hypothyroidism has been extensively studied. Feely and Isles have reported a prevalence of $2.7 \%$ of overt hypothyroidism in diabetic patients and up to $30 \%$ for subclinical hypothyroidism. ${ }^{13}$ Several other authors have reported a prevalence of $10.8-13.4 \%$ of thyroid diseases in diabetic patients and the highest rate was recorded among Type I diabetic patients.

In our study, we found that the mean maternal age of women with hypothyroidism alone, was lower compared to women with Diabetes alone, or in those with combined endocrinopathy. Tirosh et al found no such difference in maternal age in their study. ${ }^{14}$ In our study, women with dual endocrinopathies had a higher rate of infertility treatments, delayed conception $(21.4 \%)$ and previous preterm births (13.2\%). A similar observation has been reported by Tirosh et al. ${ }^{14}$

In the current study, significantly higher incidence of severe preeclampsia was noted in women with both DM and hypothyroidism (28.6\%) than in the other 2 study groups, which was similar to that reported by Tirosh et al $(25 \%) .{ }^{14}$ Many authors have reported a higher rate of pregnancy related hypertensive disorders in women with both overt and subclinical hypothyroidism than the general population. ${ }^{12,15-17}$ Similarly the risk of developing hypertensive disorders was 1.5 times greater among women with $\mathrm{GDM}^{18}$ while the risk of eclampsia was 1.8 times greater than in other pregnant women. ${ }^{19}$ These endocrinopathies which modify the effect of one another and are influenced by metabolic processes might have an additive influence on the risk to develop hypertensive disorders during pregnancy. ${ }^{14}$

Young et al and Beucher et al have documented a higher risk for preterm delivery in both GDM and preGDM. ${ }^{20,21}$ A similar tendency for preterm labour has also been reported in women with hypothyroidism. ${ }^{22,23}$ Tirosh et al have stated that was lack of independent association between preterm births and the combined endocrinopathy of DM and hypothyroidism. ${ }^{14}$ In our study the incidence of preterm births was also significantly high (18.8\%) in 
women with dual endocrinopathy. This could be explained by the fact that this group also had a higher rate of obstetric complications like polyhydramnios, placental abruption and hypertensive disorders which could have led to induced or spontaneous preterm deliveries.

In our study, women with combined endocrinopathies had a higher rate of first trimester abortions (10.6\%), obstetric complications like polyhydramnios $(35.7 \%)$, placental abruption $(21.4 \%)$ and postpartum haemorrhage (32\%) which were statistically significant compared to other groups.

In the present study, we noted that the rates of labour induction were almost the same in those with dual endocrinopathy $(36 \%)$ and in those with diabetes alone $(38.7 \%)$. We observed that the caesarean rates were higher in the combined endocrinopathy group (48\%). Tirosh et al in their study found that combined endocrinopathy is an independent risk factor for caesarean section and reported a higher incidence of both urgent and nonurgent caesarean section (44.4\%) in such women. $^{14}$

Intrauterine deaths were significantly higher in the combined endocrinopathy group $(7.1 \%)$ in our study while this was not observed in a similar study by Tirosh et al. ${ }^{14}$ The incidence of macrosomia was almost the same in diabetes alone group $(21.4 \%)$ and in the dual endocrinopathy group (17.5\%) which was in accordance with that reported by Tirosh et al.

The major limitation of this study is the relatively small number of subjects evaluated and lack of documentation regarding glycemic control which also could have influenced the fetomaternal outcome.

\section{CONCLUSION}

The combination of DM and hypothyroidism in pregnancy is associated with higher rates of infertility, preterm births, hypertensive disorders and caesarean sections. The observations made in our study, particularly the increased risk of abortions, placental abruption, polyhydramnios, PPH and intrauterine deaths in women with dual endocrinopathy highlight the need for closer surveillance during pregnancy for better outcome. Moreover, it will be beneficial if a woman diagnosed with one endocrinopathy is screened for the other.

Funding: No funding sources Conflict of interest: None declared

Ethical approval: The study was approved by the Institutional Ethics Committee of Thanjavur medical college, Thanjavur, Tamilnadu, India

\section{REFERENCES}

1. American Diabetes Association, "Diagnosis and classification of diabetes mellitus (Position
Statement). Diabetes Care. 2011;34 (supplement 1):S62-9.

2. King H. Epidemiology of glucose intolerance and gestational-diabetes in women of childbearing age. Diabetes Care. 1998;2(2):B9-13.

3. Lapolla A, Dalfra MG. Epidemiology of diabetes in pregnancy: a review of Italian data. Diabetes, Nutrition and Metabolism. 2004;17(6):358-67.

4. Casey BM, Lucas MJ, Mcintire DD, Leveno KJ. Pregnancy outcomes in women with gestational diabetes compared with the general obstetric population. Obstetrics and Gynecology. 1997;90:869-73.

5. Barahona MJ, Sucunza N, Garcia-Patterson A, Hernandez M, Adelantado JM, Ginovart G. Period of gestational diabetes mellitus diagnosis and maternal and fetal morbidity. ACTA Obstetricia et Gynecologica Scandinavica. 2005;84:622-7.

6. Langer O, Yogev Y, Most O, Xenakis EM. Gestational diabetes: the consequences of not treating. American Journal of Obstetrics and Gynecology. 2005;192:989-97.

7. Smallridge RC, Ladenson PW. Hypothyroidism in pregnancy: consequences to neonatal health. Journal of Clinical Endocrinology and Metabolism. 2001;86:2349-53.

8. LeBeau SO, Mandel SJ. Thyroid disorders during pregnancy. Endocrinology and Metabolism Clinic. 2006;35:117-36.

9. Nambiar V, Jagtap VS, Sarathi V, Lila AR, Kamalanathan S, Bandgar TR, Menon PS, Shah NS. 2011. Prevalence and impact of thyroid disorders on maternal outcome in Asian-Indian pregnant women. Journal of Thyroid Research. 2011. Article 429097, 6 pages.

10. Abalovich M, Gutierrez S, Alcaraz G, Maccallini G, Garcia A, Levalle O. Overt and subclinical hypothyroidism complicating pregnancy. Thyroid. 2002;12:63-8.

11. Hallengren B, Lantz M, Andreasson B, Grennert L. Pregnant women on thyroxine substitution are often dysregulated in early pregnancy. Thyroid. 2009;19:391-4.

12. Poppe K, Glinoer D. Thyroid autoimmunity and hypothyroidism before and during pregnancy. Human Reproduction Update. 2003;9:149-61.

13. Feely J, Isles TE. Screening for thyroid dysfunction in diabetics. British Medical Journal. 1979;1:1678.

14. Tirosh D, Benshalom-Tirosh N. Hypothyroidism and diabetes mellitus - a risky dual gestational endocrinopathy. Peer J. 2013;1:e52.

15. Leung AS, Millar LK, Koonings PP, Montoro M, Mestman JH. Perinatal outcome in hypothyroid pregnancies. Obstetrics and Gynecology. 1993;81:349-53.

16. Sahu MT, Das V, Mittal S, Agarwal A, Sahu M. Overt and subclinical thyroid dysfunction among Indian pregnant women and its effect on maternal and fetal outcome. Archives of Gynecology and Obstetrics. 2010;281:215-20. 
17. Wilson KL, Casey BM, McIntire DD, Halvorson LM, Cunningham FG. Subclinical thyroid disease and the incidence of hypertension in pregnancy. Obstetrics and Gynecology. 2012;119:315-20.

18. Bryson CL, Ioannou GN, Rulyak SJ, Critchlow C. Association between gestational diabetes and pregnancy-induced hypertension. American Journal of Epidemiology. 2003;158:1148-53.

19. Coghill AE, Hansen S, Littman AJ. Risk factors for eclampsia: a population-based study in Washington State, 1987-2007. American Journal of Obstetrics and Gynecology. 2011;205:553.

20. Yang J, Cummings EA, O’Connell C, Jangaard K. Fetal and neonatal outcomes of diabetic pregnancies. Obstetrics and Gynecology. 2006;108:644-50.
21. Beucher G, Viaris de Lesegno B, Dreyfus M. Maternal outcome of gestational diabetes mellitus. Diabetes and Metabolism. 2010;36:522-37.

22. Casey BM, Dashe JS, Wells CE, McIntire DD, Byrd W, Leveno KJ, Cunningham FG. Subclinical hypothyroidism and pregnancy outcomes. Obstetrics and Gynecology. 2005;105:239-45.

23. Stagnaro-Green A, Chen X, Bogden JD, Davies TF, Scholl TO. The thyroid and pregnancy: a novel risk factor for very preterm delivery. Thyroid. $2005 ; 15: 351-7$.

Cite this article as: Amudha $\mathrm{P}$, Karthika Devi A, Manochithra B, Delphin Supriya J. Implications of combined endocrinopathy of diabetes mellitus and hypothyroidism on pregnancy. Int J Reprod Contracept Obstet Gynecol 2017;6:266-70. 